\title{
"Los que necesitan y los que no". Una aproximación a las prácticas políticas en Villa los Vientos (ciudad de Córdoba).
}

\author{
Marina Liberatori
}

Maestría en Antropología y Doctorado en Ciencias Antropológicas, Museo de Antropología, Facultad de Filosofía y Humanidades, Universidad Nacional de

Córdoba. E-mail: marinaliberatori@gmail.com

\begin{abstract}
Resumen
En este artículo analizaré las prácticas políticas de las personas que viven en Los Vientos, especialmente las referidas a la participación del Estado municipal en la villa. Veremos como un tornado, ocurrido en el año 2003, se erigió como un acontecimiento que generó un criterio de legitimidad para que algunas personas pudieran mejorar su calidad de vida. Este criterio se basó en la condición de haber sido directamente afectados por la catástrofe para recibir materiales de construcción y alimentos por parte del Estado. Una familia, residente de la villa, se posicionó como intermediaria entre la Municipalidad y los demás vecinos, cobrando legitimidad para decidir a quién le correspondía y a quién no la ayuda brindada. Esto ocasionó múltiples conflictos entre algunas personas que cuestionaron esta lógica de distribución, realizando diversas estrategias para recibir apoyo, aún sin haber sufrido las consecuencias del ventarrón. El tornado suscitó además algunas representaciones y prácticas diferentes en torno a la noción de política entre las personas. Veremos entonces cómo ésta última no puede ser abordada sin tener en cuenta los contextos particulares y las relaciones sociales que las propias personas tejen, a partir de las cuales organizan y dan sentido al mundo.
\end{abstract}

Palabras clave: villa; prácticas políticas; estado; Córdoba.

"The ones who need and the ones that no". An approach to the political practice in Villa el Viento (Córdoba city)

\begin{abstract}
This article will discuss the political practices of people living in the winds slums, especially those relating to Municipal State involvement in the village. We'll see how a tornado, which occurred in the year 2003, emerged as an event that generated a criterion of legitimacy for some people could improve their quality of life. This criterion was based on the condition of having been directly affected by the disaster to receive construction materials and food by the State. A family who lives in the slums positioned as an intermediary between the Municipality and the other neighbors, claiming legitimacy to decide who needed and who not the State's assistance. This caused many conflicts between some people who questioned this logic of distribution, making different strategies for support, even though they never suffered the consequences of the tornado. The tornado also raised some representations and different practices around the notion of politics among people. Then we will see how this notion cannot be addressed without taking into account the particular contexts and social relations that weave people themselves and from which they organize and give meaning to the world.
\end{abstract}

Key words: slums; political practices; state; Córdoba.

En este artículo analizaré las prácticas políticas de algunas personas que viven en Los Vientos ${ }^{1}$ especialmente referidas a la participación del Estado en la villa. El mismo se enmarca en mi tesis de maestría que intenta abordar los diferentes sentidos sobre miedos y peligros que se configuran en la villa. Al comenzar el trabajo de campo, a principios de 2009, las primeras charlas informales

\footnotetext{
1 Los Vientos es un nombre ficticio al igual que todos en este artículo, inventados con el fin de proteger la identidad e intimidad de las personas que colaboran con este trabajo.
}

que mantuve allí con los vecinos fueron acerca de un tornado acontecido en el año 2003. Este suceso marcó las vivencias de los habitantes de ese lugar tornándose en algo para temer, incluso mucho tiempo después de lo sucedido.

Lo que me interesa destacar en este texto es que el tornado significó, entre otras cosas, la percepción de un cambio en la manera en que el Estado se hizo presente en la villa. Después de la catástrofe la gestión del entonces 
intendente municipal² entregó a los damnificados materiales para reconstruir sus casas. También se ocupó, según sostienen algunos vecinos, "personalmente" ${ }^{\text {"3 }} \mathrm{de}$ realizar gestiones para facilitar infraestructura para los servicios de agua de red y energía eléctrica, faltantes hasta entonces en la villa.

Según las personas que viven en Los Vientos, el requisito para recibir materiales de construcción y alimentos por parte de la Municipalidad era haber sido afectados por el tornado, ya que hubo zonas que no sufrieron las consecuencias del ventarrón.

Una familia, residente de la villa, se posicionó como intermediaria entre la Municipalidad y los demás vecinos, cobrando legitimidad para decidir a quién le correspondía y a quién no la ayuda brindada por el Estado. Esto ocasionó múltiples conflictos entre algunas personas que cuestionaron esta lógica de distribución de los recursos, realizando diversas estrategias para recibir apoyo. Surgieron controversias respecto de cuáles debían ser los criterios a partir de los que se tornaba legítimo recibir dicha ayuda. Estas ideas contrapuestas desataron disputas y tensiones entre los vecinos y mencionada familia.

La construcción de un Centro Integrador Comunitario $(\mathrm{CIC})^{4}$ en la villa, fue otra de las consecuencias políticas que trajo el tornado. La familia citada obtuvo un empleo en esta dependencia municipal despertando sospechas y contrariedades entre algunos vecinos.

A partir de este hecho se suscitaron, entre las personas, algunas representaciones y prácticas diferentes en torno a la noción de política. Veremos entonces cómo ésta última no puede ser abordada sin tener en cuenta los contextos particulares y las relaciones sociales que tejen las propias personas y a partir de las cuales organizan y dan sentido al mundo.

\section{Lo que el viento se llevó...}

'Acá sopla un viento y todos empezamos a gritar desesperados' (Diario de campo, 2009)

Los Vientos es una de las villas más grandes y más antiguas

\footnotetext{
2 Luis Juez era el intendente de la ciudad de Córdoba, en el año 2003, al momento en que aconteció el tornado.

${ }^{3}$ De ahora en adelante, el uso de las las itálicas entrecomilladas hace referencia a las expresiones y categorías nativas, las comillas simples son para citar relatos de campo y también para relativizar algunas de mis propias expresiones; y las comillas dobles se usan para referir a las citas textuales de autores incorporadas al texto.

${ }^{4}$ Los Centros Integradores Comunitarios constituyen un modelo de gestión pública que implica la integración y coordinación de políticas de Atención Primaria de Salud y Desarrollo Social. Son dependencias municipales que tienen la finalidad de contribuir a mejorar la calidad de vida de las personas. En Córdoba existen tres $\mathrm{CIC}$ ubicados en villas y barrios populares de la ciudad. Para mayor información consultar en: www.desarrollosocial.gov.ar
}

de Córdoba. Se encuentra ubicada en la zona oeste de la ciudad, hacia adentro de la ruta 20 camino a Villa Carlos Paz. Según el INDEC (2001), tiene una población que alcanza las 12.000 personas aproximadamente. Comparte ciertas características con otras villas del país, como la precariedad de las condiciones habitacionales y la ilegalidad de los terrenos ocupados (Gutiérrez, 2004).

La villa se fue conformando en los años `70, década en la que comenzó, en América Latina, un proceso de modernización y reorganización tanto de las estructuras económicas como de las relaciones sociales y la vida cotidiana. (Lechner, 1998) Por esos años, en nuestro país se desencadenaron procesos de exclusión vinculados principalmente con transformaciones producidas en el mercado de trabajo.

Estos cambios en el sector laboral se relacionan con empleos poco estables, desempleo y la consecuente exclusión de vastos grupos sociales del mercado de consumo. (Isla y Míguez, 2003) A su vez, Los Vientos registró un importante crecimiento poblacional debido a la llegada masiva de habitantes expulsados de barrios aledaños y de otros asentamientos cercanos, durante la crisis que azotó a Argentina a comienzos de la última década.

La mayoría de las personas que allí habitan tienen empleos informales y también reciben algún tipo de plan social. ${ }^{5}$ En general, los hombres, con los que he conversado, trabajan en el sector de la construcción, como guardias de seguridad en fábricas o juntando cartones y papel en sus carros. Mientras que las mujeres lo hacen en casas de familia como empleadas domésticas, lo que se dificulta, muchas veces, porque no tienen con quién dejar a sus hijos. También es bastante común que la gente improvise en sus viviendas algún negocio de venta de artículos y comestibles, como despensas, quioscos y pollerías.

Como dijimos anteriormente, en el año 2003 se desató un tornado en la ciudad de Córdoba que afectó particularmente a Los Vientos y zonas aledañas. En la villa dejó el saldo de una muerte, varios heridos y la destrucción de una importante cantidad de viviendas.

"Y el tornado fue terrible. Me acuerdo que yo
estaba en mi pieza que era toda de chapa.
Primero hacía mucho calor y después empezaron

\footnotetext{
${ }^{5}$ Los planes sociales refieren a diferentes tipos de subsidios y planes de empleo que el gobierno nacional, provincial o municipal otorga a personas que se encuentran desocupadas o subempleadas. La mayoría de estos planes exigen como contraprestación la realización de tareas en proyectos comunitarios, productivos y también educativos. Por ejemplo, trabajos en comedores, bibliotecas populares, cortaderos de ladrillos, como también realizar cursos en alguna institución educativa. Dicha contraprestación laboral es aproximadamente de cuatro horas la jornada. Estos tipos de planes fueron progresivamente reemplazados por otros subsidios. Primero los Programa Familia y actualmente la Asignación Universal por Hijo que es la ayuda que la mayoría de los vecinos recibe en Los Vientos. Para más información consultar en www.trabajo.gov.ar
} 
a caer gotas grandes. Ahí nomás se levantó un viento y empezó todo (...) estábamos muertos de miedo. Y era todo un quilombo, los techos se volaban, se volaban los muebles de las casas, televisores. La gente corría, los chicos se perdían (...) hasta un muerto tuvimos que sacar de una de las casas de allá del fondo (...)" (Carlos, septiembre de 2010) ${ }^{6}$

La catástrofe tornó visible social y políticamente las precarias condiciones habitacionales en las que viven las personas de Los Vientos. Esta fue la zona más afectada, a diferencia de los barrios aledaños cuyas viviendas están, en su mayoría, construidas de bloques y ladrillos. Veremos cómo después del tornado la villa comenzó un proceso en que se delimitaron las calles, se dividieron los lotes en manzanas y se legalizaron los servicios de luz y agua. Estos cambios no acontecieron en todos los sectores de la villa de manera homogénea, fueron parte de un proceso político que trajo aparejadas algunas consecuencias.

\section{El tornado: un antes y un después.}

"Vos no te imaginas cómo era la vida antes de tener luz y agua corriente. Era muy complicado, nos enganchábamos del cableado que pasaba por el barrio del lado, pero la luz llegaba con un voltaje muy bajo, 80 suponete. Entonces si prendías el televisor tenías que apagar todas las bombitas (focos de luz) Y ni que hablar de tener calefón eléctrico. Los vecinos que tenían para garrafa calentaban agua en la cocina y los que no sobre brazas"(Zuny, abril de 2009).

Zuny tiene 45 años y es la madre de Carlos, vive en Los Vientos desde 1986. Está casada con un hombre al que le dicen Chacho con quien tiene cuatro hijos, tres de los cuales viven con ellos. La cita de Zuny coincide con otros relatos de personas que fueron afectadas por el tornado y que sostienen que antes de que el mismo aconteciera se tornaba muy difícil la vida en la villa. La carencia de servicios públicos, la infraestructura paupérrima de las viviendas y las privaciones e incomodidades que esto acarreaba parecían ser las principales preocupaciones en aquel momento.

"Y después de ahí todo cambió. Es un antes y un después del tornado para Los Vientos. (...) Acá la gente lo quiere mucho a Juez (intendente municipal 2003-2007) porque él hizo mucho por la villa. Ahí nomás dio materiales para arreglar las casas (...) mi viejo la hizo ahí nomás y ayudó a otros tres vecinos. Esas casitas quedaron listas rápido, pero vos imaginate que en el tiempo en que mi viejo levantó tres casas no había ni una levantada más, recién estaban por los cimientos.

\footnotetext{
6 Carlos tiene 23 años y vive en Los Vientos desde que nació. Su familia, como veremos, ocupa una posición de poder en la villa a partir del tornado.
}

Entonces los de la Municipalidad lo contrataron a mi viejo y a otros más para levantar las casas (Carlos, septiembre, 2010).

En el relato anterior Carlos afirmaba que hubo personas que no levantaron sus viviendas con el material entregado por el Estado. Por el contrario, Chacho y otros pocos vecinos si lo hicieron y en un lapso breve de tiempo. Desde la visión de Carlos, esa fue la razón por la cual la Municipalidad decidió contratar a estos hombres, con la finalidad de reconstruir las viviendas de las personas damnificadas.

Meses más tarde, tras la construcción del CIC, contrató a Zuny. Esta última al igual que Chacho, tiene un puesto de trabajo por contrato y cumple seis horas diarias allí. El trabajo de Zuny consiste, según ella, en acompañar al equipo técnico municipal constituido por trabajadores sociales, psicólogos y médicos generalistas en las tareas relacionadas con la comunidad. Por ejemplo, recorre con ellos la villa para informar a los vecinos sobre campañas de vacunación o sobre cómo inscribirse para recibir un plan, entre otras tareas.

Al parecer después del tornado mejoraron algunas condiciones en la villa, pero sólo en las zonas afectadas por el tornado. Es así como Los Vientos quedó dividida en dos partes bien diferenciadas: aquella por la que pasó el tornado y fue reconstruida y aquella que quedó igual. En palabras de mis interlocutores la parte de "adelante y la del fondo."

La categoría adelante no se corresponde necesariamente con una locación geográfica de la villa, sino más bien con la percepción de quiénes viven en uno u otro lado. Así ésta varía y es definida según se viva en una u otra zona. En otras palabras, todos perciben al sector donde viven como la parte de adelante y los del fondo serían los otros. "La mejor parte es esta parte principal nomás, porque después si te fijas bien están todas las casas venidas abajo" (Zuny, marzo de 2009)

La parte de adelante, para los que allí viven, es la principal de la villa porque coincide con la zona recuperada tras la catástrofe. Por el contrario, en "el fondo" aún son mayoría las casas construidas de chapa y madera y la carencia de los servicios públicos antes mencionados.

La familia de Zuny, los Corola, han vivido desde siempre "adelante" y como ya dijimos, tuvieron una participación muy activa en la reconstrucción de este sector de la villa. Podría decirse que a, partir del tornado, se posicionaron como intermediarios legítimos entre la Municipalidad y las personas afectadas por el tornado. Analizaremos este punto más detalladamente párrafos más adelante.

\section{Zuny, "una persona muy política"7}

\footnotetext{
${ }^{7}$ Esta expresión fue realizada por Zuny en marzo de 2009 durante una de nuestras primeras charlas informales.
} 
Como esbozamos anteriormente, el tornado dio paso para la construcción, en Los Vientos, de uno de los tres $\mathrm{CIC}$ que se encuentran en la ciudad de Córdoba. Allí se realizan una serie de actividades culturales de las que participan los vecinos cotidianamente, como así también reuniones en las que se discuten temas que las personas, con las que he conversado, señalan como "importantes para la villa". Como por ejemplo, la conformación del centro vecinal, la gestión de recursos del CIC, entre otros.

El CIC comparte el espacio físico con el UPAS ${ }^{8}$. Esto supone la construcción de relaciones cotidianas entre el personal médico, los trabajadores sociales y Zuny. Ella además de realizar las actividades conjuntas con el personal del $\mathrm{CIC}$, acompaña a los médicos con las tareas vinculadas con la comunidad. Los 'acompañamientos' que realiza Zuny a los profesionales enviados por la Municipalidad tienen que ver con que ella 'vive ahí y se supone que conoce a las personas y que éstas le tienen confianza.

Una tarde que estábamos tomando mate en el CIC Zuny me decía:

"Yo no decido a quien darle o no, consulto con la trabajadora social para evitar problemas. Por ejemplo, vino una señora que tenía chinches en su casa y tuvo que quemar colchas y colchones, entonces yo le consegui" (Zuny, abril de 2009)

En la cita anterior, Zuny afirma que ella consulta siempre con los trabajadores sociales para evitar problemas. Sin embargo, en la práctica no siempre es así ya que no tiene la obligación formal de hacerlo. Como empleada del CIC Zuny puede decidir sobre algunos recursos de esa dependencia municipal sin necesidad de consultar con los técnicos y profesionales.

Así por ejemplo, si algún vecino necesita ropa, una canasta de alimentos, cospeles o usar la camioneta de la Municipalidad, es Zuny quién ayuda a resolver esas cuestiones. Es a ella a quien deben consultar si necesitan utilizar, por ejemplo, el salón de usos múltiples, algunos insumos como la garrafa o aulas para realizar una reunión.

Los trabajadores sociales intervienen en las decisiones sobre la gestión de planes sociales, consultas en juzgados, entre otras cosas. Por ejemplo, estos profesionales dieron aviso a un juzgado sobre el caso de doña Marcela, una señora que vive en la villa desde hace dos años, porque, según me contó Zuny, "no manda a los chicos al colegio

\footnotetext{
8 Los UPAS o Unidades de Atención Primaria de la Salud son puestos municipales de salud creados con la finalidad de brindar una primera atención para las personas del barrio o zonas aledañas. Estos UPAS se encuentran en muchos barrios de la ciudad de Córdoba, principalmente los más empobrecidos. Desde los UPAS se realizan campañas de prevención de enfermedades que consisten en charlas y talleres. También se colocan vacunas, DIUS y se entrega cotidianamente leche, anticonceptivos y otros medicamentos que requieran los pacientes.
}

y eso que cobra la Asignación". Un día charlando con doña Marcela me contó que tras ese aviso los del juzgado la amenazaron con quitarle a los niños. Según me dijo, está convencida que fue Zuny quien realizó la denuncia. Imagino que cree esto porque Zuny es empleada del $\mathrm{ClC}$, al igual que los trabajadores sociales que a menudo visitan a Marcela.

En la cita anterior Zuny menciona ciertos problemas que pueden ocasionarse por causa de su capacidad de decisión sobre el destino de los recursos del CIC. Estos refieren a los comentarios que circulan entre algunos vecinos respecto de que ella "les da cosas a sus amigos y no a los que tienen verdadera necesidad". (Nota de campo 2010) Tal es el caso de doña Mabel y su marido Jorge. Este matrimonio vive en la villa desde hace 11 años en diagonal a la casa de Zuny. Tienen algunos conflictos con los Corola que surgieron después del tornado, como ya veremos más adelante.

Desde el punto de vista de doña Mabel y Jorge, Zuny distribuye los recursos otorgados por la Municipalidad según su propia red de relaciones sociales, desconociendo las necesidades de la villa. Estas personas también sostienen que los Corola se unieron al partido de Luís Juez, después del tornado, para conseguir los puestos de trabajo en la Municipalidad.

En relación con esto Zuny me explicaba que al trabajo que tiene no lo obtuvo por "amiguismos políticos": "Pero a mí nadie me ha regalado nada, el puesto que tengo en la Municipalidad, (se refiere a su trabajo en el CIC), me lo gané laburando. Y los del partido saben que con migo no, que si me piden que les junte gente les voy a decir que no." (Zuny, junio 2009)

Zuny es por propia definición una "persona muy política" y desde hace algunos años pertenece al Partido Nuevo ${ }^{9}$. Ella afirma tener una amistad con el ex intendente Luís Juez y su hermano Daniel Juez, también perteneciente al Partido Nuevo. Según Zuny los Juez la conocen y saben que ella tiene sus límites y que "no usa a la gente de la villa para hacer política." Lo que lleva a preguntarme ¿Qué significa para Zuny usar a la gente para hacer política? ¿Cuáles son los sentidos que se configuran para ella respecto de esta práctica?

En relación con lo que venimos exponiendo Frederic (2004) investiga procesos políticos en villas y barrios empobrecidos de Buenos Aires y analiza cómo la política y la moral se imbrican mutuamente. Para ella no es posible analizar a la política sin tomar en cuenta las evaluaciones morales que las personas hacen de ella. Más aún es a

\footnotetext{
${ }^{9}$ El Partido Nuevo se formó en el año 200l y terminó de constituirse jurídicamente en agosto de 2003. En el mes de octubre de ese año hubo, en la ciudad de Córdoba, elecciones para elegir intendente y este partido ganó las mimas. Para más información consultar: www. partidonuevocordoba.com.ar
} 
través de la moralidad que los actores se posicionan políticamente. Frederic relativiza ciertas posiciones académicas y también de sentido común que consideran que el "clientelismo" y la corrupción son manifestaciones de la moralidad política y que revisten de un sentido social y políticamente negativo.

"Esto sugiere que hay una política buena o moral y otra nefasta, a pesar de que parece tener más legitimidad que la que se imagina buena política. Acá no se trata de saber si tal o cual aspectos de las prácticas políticas es bueno o malo, ni lo que sería deseable, sino de establecer cómo funcionan determinadas prácticas en un sistema social particular" (Puex 2006:185)

Sobre esta línea, Puex (2006) arriba a la conclusión de que las "relaciones clientelares" son demasiado complejas para reducirlas a una dependencia y manipulación de los sectores populares, como se ha esbozado en algunos estudios. Esta autora sostiene que existe una tendencia en la academia que tiende a comparar modelos políticos y a establecer tipos ideales de los mismos. Esto explicaría el hecho de qué ciertas investigaciones estigmatizan las relaciones clientelares en Argentina, por un lado, relacionándolas con un sólo bando político (el peronismo). Por otro lado, no analizándolas dentro del conjunto del sistema político y social.

Ahora bien, si reflexionamos sobre lo que Zuny dijo podemos interpretar que considera la existencia de una política buena que sería "hacer cosas por la gente" y otra mala que representa "juntar gente para el partido. Esto último sería moralmente dudoso, ya que estaría estableciendo con las personas una relación clientelar, intercambiando la solución a ciertos problemas, como por ejemplo, el de las chinches, por algún favor político.

Por otro lado, cuando Zuny se dirige a mi lo hace sabiendo que vengo de la universidad. Zuny afirma que "no es bueno usar a la gente para hacer política" y quizás puede pensar que desde la universidad u otros sectores sociales se deslegitiman también este tipo de prácticas.

Según Frederic (2004) la moralidad posee dos elementos que no pueden pensarse por separado: "los códigos de conducta", que están socialmente construidos y "las formas de subjetivación" que son prácticas morales individuales. Esto explicaría por qué existen ciertos consensos sociales sobre lo que es bueno y lo que es malo, sobre lo que es 'políticamente correcto y lo que no’.

Tanto Frederic, como Puex proponen una mirada que complejiza las relaciones clientelares intentando comprender cómo son construidas por los propios sujetos. Es así como buscan diferenciarse de ciertas investigaciones que conciben a las personas como sujetos pasivos y, por tanto, plausibles de manipular. Ambas autoras sostienen que la única manera de analizar estas temáticas es atendiendo a contextos particulares y a las diferentes perspectivas de los actores en cuestión.

En una de nuestras charlas Zuny afirmaba que:

"yo prefiero ser puntera, porque yo no lo oculto, yo pertenezco a un partido que es el de Luís Juez y trabajo en esta comunidad por la gente que es lo que a mí me interesa. En cambio los otros sí, ellos te dan un plan y a cambio te piden que marches o te dicen votá a tal." (Zuny, septiembre 2009)

La categoría "otros" refiere, para Zuny, a la organización Tupac Amaru ${ }^{10}$ A esta misma pertenece Hortensia, una mujer "muy respetada" en Los Vientos, según algunos vecinos. Hortensia vive en una manzana contigua a la de Zuny, desde hace veinte años y se ha constituido en una referente a la hora de tomar decisiones en Los Vientos. Esta condición le es atribuida, en parte, por el tiempo de residencia en la villa, pero también por prestar su propia casa para llevar a cabo actividades como copa de leche, apoyo escolar, etc. Según comentarios de algunos vecinos, y de la propia Zuny, "Hortensia es una persona que sabe cómo hacer las cosas."

Zuny tiene algunas diferencias políticas con la organización Tupac Amaru y también con Hortensia:

"Yo no entiendo cómo acá en la villa hay organizaciones que tienen plata y contactos como para dar trabajo a los chicos, por ejemplo la Tupac Amaru. Yo no digo que pongan una fábrica acá, pero ellos creen que con un taller de capacitación en manufactura ya está ¿y para qué les sirve a los chicos eso si después no van a conseguir trabajo?"(Zuny, septiembre 2009)

Pregunté entonces por qué creía ella que sucedía esto respecto de Tupac Amaru,

"Porque esos son de un partido político, son kirschneristas, pero no les importa nada de la gente, sólo quieren los votos, entonces arreglan todo con un plan." (Zuny, septiembre 2009).

Cuando Zuny afirma que es una puntera pero que no "junta gente para el partido" lo hace diferenciándose de otras organizaciones como la Tupac Amaru que, según ella, sólo hacen política para "juntar gente" y no tienen un genuino interés por "hacer algo por las personas". Ella no niega su vinculación al Partido Nuevo ya que afirma que en la villa todos saben a quién apoya. Sin embargo,

\footnotetext{
${ }^{10}$ La organización Tupac Amaru nació en Jujuy bajo el liderazgo de Milagro Sala. Se extiende a lo largo de ocho provincias argentinas: Salta, Córdoba, San Juan, Mendoza, Formosa, Catamarca, La Rioja y Buenos Aires. Recibe fondos de la Nación a través de la CTA. Esta organización funda cooperativas con el propósito de brindar empleo a sus militantes. Levanta fábricas, administra comedores y copas de leche, entre otros proyectos. Para mayor información consultar www. tupacamaru.org.ar
} 
desde su visión son los otros los que tienen recursos para intercambiar un plan por la participación en una marcha o por un voto.

Por otra parte, Zuny afirma que ella "está" con el partido independientemente de los resultados políticos que este tenga o de los beneficios que pueda recibir del mismo.

"yo estoy con el partido, apoyo a Juez siempre, cuando le va bien y cuando le va mal, no como algunos que sólo están para recibir una caja de alimentos o una beca y después se van con otros partidos. Yo estoy siempre con el partido de Juez y eso es lo que él valora" (Zuny, noviembre de 2010).

En nuestras charlas, Zuny siempre se muestra con un profundo convencimiento de participar en el Partido Nuevo y parece valorar mucho esta actitud que supone una verdadera vinculación con el mismo. En cambio, desestima a aquellas personas que, como Hortensia, han participado antes de otras agrupaciones políticas y no se comprometen con ninguna en particular. Veremos esto con más detenimiento en el siguiente apartado.

\section{"Acá no queremos política. ${ }^{11 "}$}

Como dijimos anteriormente, Hortensia vive en la manzana siguiente de la de Zuny. Antiguamente participaba de una organización piquetera "Movimiento Teresa Rodríguez", pero desde hace unos años lo hace en la Tupac Amaru, brindando apoyo escolar en su casa, copa de leche y ayudando en una bloquera ${ }^{12}$ que funciona en barrio San Roque -contiguo a la villa- y que emplea a algunos jóvenes de Los Vientos. Las hijas mujeres son las que ayudan a Hortensia con la copa de leche y apoyo escolar. Estas tareas consisten por ejemplo, en preparar mate cocido, pan casero y cortar raciones de dulce de membrillo que les entregan desde la organización. También ayudan con los deberes de la escuela a varios niños de la villa.

Una tarde charlábamos con Hortensia mientras ella limpiaba en la puerta de su casa. Me contaba sobre su preocupación por los chicos de la villa vinculados a la droga y los peligros que ello implica para la seguridad de los vecinos y para la salud de esos mismos jóvenes. Mencionó el caso de Ciro, un chico que se había suicidado hace unos días: "y todo porque andaba metido con el narcotráfico. Yo siempre pido en las reuniones que nos pongan un patrullero o algo para que haya más seguridad en la villa, pero el Dago no me da pelota." (Hortensia, agosto 2009).

Dago es empleado de la Municipalidad, no vive en Los Vientos, pero acude asiduamente a las reuniones del CIC, ya que él es quien realiza el control de gestión del personal

\footnotetext{
${ }^{11}$ Comentario de Hortensia en una de nuestras charlas.

${ }^{12}$ En la bloquera se fabrican bloques de cemento y ladrillos para construcción.
}

de este centro. En una de nuestras conversaciones le pregunté a Hortensia en qué consisten estas reuniones y me respondió que es allí donde se tratan: "Los problemas de agua por ejemplo, de la luz. Si el basurero no pasa por alguna calle se hace una reunión para que empiecen a pasar y esas cosas." (Hortensia, Julio 2009).

Pregunté entonces quiénes podían participar de las reuniones y ella me dice: "Los de la Municipalidad, las organizaciones y nosotros. Todos los vecinos pueden participar"

¿Qué quiere decir Hortensia con que todos pueden participar? ¿Quiénes son esos todos a los que se refiere Hortensia? En esa oportunidad ella me contaba que aunque todos pueden tomar decisiones sobre lo que es mejor para la villa, hay quienes lo hacen pero no tienen tal derecho porque no viven allí. Así me contó sobre una discusión que tuvo con el señor Pacheco, un empleado municipal que tampoco reside en Los Vientos. Este hombre es compañero del Partido Nuevo de Chacho y Zuny, no trabaja en el $\mathrm{CIC}$, pero contribuye con la organización de un comedor para ancianos que desean abrir Zuny y Hortensia:

"Él es de afuera y pretende venir y mandar a
los vecinos para que hagan esto o lo otro. Y no
es así porque él tiene que conocer qué cosas
se necesitan, quién es guapo para trabajar y
quién no. El viene sólo a hacer política y acá no
queremos política" (Hortensia, septiembre de
2009).

Como vemos se juegan las nociones de 'adentro' y 'afuera' como dimensiones fundamentales para analizar quién puede y quién no tomar decisiones. Los que viven en la villa son los que saben cómo son las cosas, qué se necesita, quiénes trabajan, quiénes merecen y realmente necesitan ayuda. Son los de 'adentro' los que tienen derecho a participar. Por el contrario, los de 'afuera'- aquellos que vienen a realizar proyectos desde las organizaciones sociales, la iglesia o los partidos políticosno deberían participar de las reuniones.

Por otro lado, según Hortensia todos pueden participar, pero en la práctica no todos los vecinos acuden a las reuniones. Cuando le pregunté por esto me respondió que son siempre los mismos los que van: "porque a los demás no les interesa cambiar las cosas, no les interesa hacer cosas por la villa, no les interesa progresar" (Hortensia, septiembre de 2009).

Al parecer "hacer algo por la villa" o participar de las reuniones, de las actividades se relaciona con querer progresar y ese progreso supone pensar en el bien común de Los Vientos. Lo cierto es que, para Hortensia, no sólo son los de afuera los que no deberían participar, sino que no todos los vecinos parecen tener la misma 
legitimidad para hacerlo. Sobre este punto, considero que no se pueden dejar de lado las posiciones de poder que personas como Hortensia y Zuny tienen en Los Vientos y que las legitima para decidir qué es mejor para la villa.

Por otro lado, "venir a hacer política" parece ser una práctica reprochable para Hortensia, ya que sería opuesta a "trabajar para la villa", pero ¿qué significa esto para ella al fin y al cabo? En una oportunidad charlábamos con Hortensia sobre lo que era hacer política: "es apoyar a un político, conseguirle afiliados y eso yo no lo voy a hacer porque yo trabajo con mucha gente de distintos lados y se van a ir si apoyo a un partido, suponete que sea el de Juez" (Hortensia, septiembre 2009).

Para Hortensia apoyar a un partido es conseguirle afiliados o como dice Zuny "juntarle gente". Observamos el sentido negativo que le atribuye Hortensia a la noción de política, concebida como algo autónomo que contamina los espacios sociales de la villa (Palmeira y Heredia, 1997) y en este sentido, está desvinculada de otros campos como el religioso, el económico y el social (Balbi y Rosato, 2003). Hortensia la considera negativamente y por esto mismo rivaliza con Zuny. Le molesta que su amigo Pacheco opine y sea parte de las decisiones que se toman en las reuniones del CIC.

Lo cierto es que más allá de las rivalidades partidarias lo que existe entre estas mujeres es una puja de poder que se traduce en quién hace más cosas por Los Vientos, quién tiene más derecho de tomar decisiones y finalmente "quién es más guapo para trabajar."

\section{Necesitar o no necesitar.}

Como observamos anteriormente existen algunas diferencias entre Zuny y Hortensia respecto de la noción de política. La primera participa activamente del Partido Nuevo y ve con buenos ojos el compromiso hacia el mismo. En cambio, Hortensia lo hace en la organización Tupac Amaru, pero dice no comprometerse estrictamente con ninguna línea partidaria, porque lo que a ella le interesa no es hacer política sino "hacer algo por la villa". Sin embargo, ambas parecen compartir la idea de que no es bueno "juntar gente para un partido"que sería lo contrario de trabajar para que Los Vientos progrese.

A pesar de las tensiones que pueden existir entre estas mujeres, cabe destacar que ambas gozan de cierta legitimidad para decidir qué es bueno para la villa. Esto se les atribuye por el tiempo de residencia en Los Vientos, pero también por la capacidad de ambas de movilizar los recursos otorgados por el Estado, en un caso y por una organización política, en el otro.

En relación con el punto anterior analizaremos con mayor detalle la posición de poder que ocupan Zuny y su familia, los Corola, a partir del tornado. Retomando lo ya expuesto respecto de este acontecimiento, vimos que los Corola contribuyeron con la reconstrucción de las casas que habían sido destruidas por el viento. La Municipalidad contrató a Chacho para continuar con el emprendimiento de mejorar las condiciones habitacionales de una zona de la villa, la afectada por la catástrofe.

Este hecho les ocasionó a los Corola algunos conflictos con aquellas personas que no sufrieron las consecuencias directas del ventarrón. Tal es el caso de doña Mabel y Jorge, vecinos que hace relativamente poco que habitan en los Vientos, a comparación de los Corola. Como ya dijimos este matrimonio vive desde hace 11 años con sus cuatro hijos en la parte de "adelante", casi al frente de la casa de Zuny y Chacho.

Una mañana mientras tomábamos mate con Mabel, me contaba sobre el tornado:

"(...) Y la Zuny nunca me dio nada para mi ranchito. Yo estaba en la lista porque mi marido se había anotado esa noche del tornado y cuando le fui a pedir me dice: "no doña Mabel si a usted no le pasó nada en su casa". Pero yo estaba en la lista de materiales. Igual nunca le dije nada. ¿Para qué? Tampoco voy a andar mendigando para que me den algo, pero yo estaba en la lista" (Mabel, noviembre de 2010).

Según Mabel, su rancho no había sufrido las consecuencias del paso del ventarrón, pero ellos se habían anotado en "la lista"para recibir los materiales y poder así arreglar su vivienda. Escuchando diferentes relatos pude reconstruir que el origen de esa "lista" se remonta a la noche siguiente de acontecido el tornado.

Mabel afirma que oficiales de la policía rodearon a la villa prohibiendo la entrada para evitar robos de barrios aledaños. Me contó que durante las primeras horas hubo muchos saqueos de gente que se aprovechaba de la situación. Entonces enviaron oficiales para que controlaran el caos en que había quedado todo. También fue Luís Juez "personalmente" con su hermano y empleados municipales. Al parecer fueron ellos los que sugirieron que los vecinos que habían perdido sus viviendas se anotaran en una lista.

Los Corola fueron los encargados de guardar la lista con las personas afectadas, para entregársela luego a la Municipalidad. Así esta última les daría cajas de alimentos, materiales de construcción, frazadas, colchones, entre otras cosas. Durante una charla que mantuve con Carlos, el hijo mayor de los Corola él me decía que:

"(...) la gente se robaba los materiales y a mí me daba una bronca. Acá venían unos arquitectos a repartir materiales y pasaban casa por casa y ellos sabrán porque han leído, pero no tienen 
ni idea de la cantidad que hace falta. Entonces la gente de acá se aprovechaba y les pedía, suponete 7 bolsas cuando necesitaban $3 y$ después vendían las que les sobraban. Vos vieras, había otros que no les había pasado nada por el tornado y rompían su casa con una maza y después iban y pedían materiales "mire cómo me dejó la casa el tornado". „Y a mí me daba una bronca! Porque yo prefiero que les hubieran dado a los que realmente necesitaban y el tornado les había destruido las casas. Entonces yo lo ayudaba a mi papá a repartir y llamábamos a la Municipalidad y les decíamos "no le des a tal, a este otro dale tres bolsas nada más". Y la gente nos empezó a agarrar bronca, decían "pero que te haces vos si las cosas no son tuyas, que andas cuidando las cosas de la Municipalidad" (Carlos, septiembre de 2010).

Lo expuesto anteriormente nos brinda un panorama sobre algunos de los conflictos que se suscitaron después del tornado en relación a la intervención de Zuny y su familia. Al hacerse cargo de la "lista" ellos estaban en una posición de cierta legitimidad para decidir quién necesitaba los recursos de la Municipalidad y quién no. Lo curioso es que desde un punto de vista más estructural todos necesitaban arreglar sus viviendas, independientemente del tornado.

Se vuelve interesante reflexionar cómo los Corola adoptaron la lógica municipal de distribución de los alimentos y materiales y más aún se posicionaron como intermediarios entre la municipalidad y los vecinos. De alguna manera, se constituyeron en guardianes morales para que esa lógica se cumpliera por todos.

Cabe destacar aquí el poder coercitivo del Estado (Weber, 1987) para imponer qué criterios eran válidos y legítimos frente a la catástrofe. Criterios que encontraron correlato en el accionar de Zuny y su familia, pero no así en todos los vecinos.

Podemos observar que a pesar de la dominación que ejercen las estructuras estatales en las vidas de las personas, éstas poseen cierto margen de acción. (Bourdieu, 1991) Así podemos explicar por qué hubo vecinos que desarrollaron estrategias como destruir sus viviendas para poder acceder a la ayuda brindada por el Estado, a pesar de no haber sido afectados por el tornado.

De la misma manera, hubo personas que robaron los materiales e incluso aquellas que aún recibiendo por vías legales estos recursos, decidieron utilizarlos para fines diferentes a los impuestos por la Municipalidad. Los vendieron y así obtuvieron réditos económicos de los mismos.

Estas estrategias no fueron bien vistas por los Corola, la "bronca" de Carlos nos orienta para pensar en algunos valores morales que se hicieron presentes en esta situación. Para Balbi (2000) los valores morales están relacionados con el "producto histórico de procesos sociales específicos que pueden y deben ser analizados etnográficamente" (Balbi 2000: 12). Esto supone, para el autor, la interdependencia de los sujetos y la aceptación de valores comunes.

Se podría decir que la familia de Zuny consideró moralmente correcto ayudar a los que "realmente necesitaban". Lo que se puso en juego en ese momento fue justamente la legitimidad que construyó la familia de Zuny para decidir a quiénes les hacía falta esa ayuda. Así a partir del tornado quedó demostrado que los consensos sociales respecto de los valores comunes aceptados, no están dados de una vez y para siempre. Se trata más bien de procesos flexibles que se van reacomodando de acuerdo a la puja de intereses que se dan en el espacio social.

\section{Algunas conclusiones}

El tornado, acontecido en el año 2003, se erigió como un acontecimiento que generó un criterio de legitimidad para que algunas personas, que viven en villa Los Vientos, pudieran mejorar su calidad de vida. Esto se dio a partir de la gestión de los sistemas de servicios como el agua de red, energía eléctrica, el loteo de los terrenos- aunque no los títulos de propiedad, ya que se trata de terrenos usurpados- y la demarcación de algunas calles.

A partir de esto me pregunto: ¿Por qué fue a partir del tornado que se visibilizaron, para la Municipalidad, las precarias condiciones habitacionales de villa Los Vientos? ¿Por qué tras una situación de catástrofe natural estas personas se convirtieron en sujetos legítimos para recibir ayuda del Estado?

Vimos cómo el Estado impuso ciertas lógicas de distribución de los recursos que beneficiaron sólo a las personas afectadas por el tornado. Este criterio fue aceptado especialmente por los Corola, una familia que se posicionó como intermediaria entre la Municipalidad y los vecinos de Los Vientos. Sin embargo, hubo quienes cuestionaron este criterio valiéndose de estrategias para poder recibir esta ayuda aunque, desde el punto de vista de los Corola y de la lógica distribucionista impuesta por el Estado, "no necesitaban". De esta manera, observamos que la coerción de las estructuras no es siempre tan determinante de la posibilidad de acción de las personas. (Bourdieu, 1991)

Por otra parte señalamos que existen tensiones en Los Vientos respecto de diferentes concepciones sobre el hacer política. Así, Zuny, según su propia opinión es "puntera" del Partido Nuevo y Hortensia participa en la organización Tupac Amaru. Para esta última la política tiene un sentido moralmente negativo (Frederic, 2004) 
ya que respondería a intereses partidarios y no de la comunidad. Desde esta perspectiva la política sería aquello por lo cual se usa a la gente para que se afilie a un partido político determinado.

Para Zuny, en cambio, la política es lo que le permite "hacer algo por la gente" y por eso ella no lo oculta. Desde su visión es moralmente mejor autoproclamarse como puntera de un partido, que participar de una organización que cambia planes por marchas y "no termina haciendo nada por la gente". Lo que se disputa en relación al capital social, es el poder para legitimar quién puede hacer política y quién no. También se disputan el saber hacer, la trayectoria en la villa y el hecho de ser referentes allí.

De esta manera, al analizar etnográficamente prácticas políticas se relativizan y se complejizan ciertas representaciones que señalan que es el Estado o los partidos políticos, es decir la política con mayúscula, los que están legitimados socialmente para hacer política. (Balbi y Rosato, 2003)

Finalmente podemos decir que lo expuesto da cuenta de la complejidad existente entre los tejidos de relaciones que forman las personas, a través de las cuáles construyen significaciones sobre el mundo y organizan su vida cotidiana (Heredia y Palmeira, 1997). A partir del acceso y la participación en esta maraña de interdependencias y relaciones de reciprocidad, se pueden comprender, en parte, algunas experiencias, sentidos y representaciones sobre la noción de política que tienen las propias personas que viven en villa Los Vientos.

Córdoba, Noviembre de 2011.

\section{Bibliografía}

Balbi, F y A. Rosato. 2003 Representaciones sociales y procesos políticos. Estudios desde la antropología social Buenos Aires, Antropofagia.

Balbi, F. 2000 Interdependencia, memoria institucional y valores morales: fundamentos sociales de la moralidad en una cooperativa de pescadores entrerrianos. Avá. Revista de Antropología Social 2:95-111.

Bourdieu, P. 1991 El sentido práctico. Taurus, Madrid.

Bourdieu, P. 2000 Sobre el poder simbólico. En: Intelectuales, políticas y poder. Buenos Aires. EUDEBA

Frederic, S. 2004 Buenos vecinos, malos políticos: moralidad y política en el Gran Buenos Aires. Buenos Aires, Prometeo.

Gutiérrez, A. 2004 Pobre...como siempre. Estrategias de reproducción social en la pobreza. Córdoba, Ferreyra Editor.

Isla, A y D. Míguez. 2003. Heridas Urbanas. Violencia delictiva y transformaciones sociales en los noventa. Buenos Aires. Ed. de las ciencias.

Lechner, N. 1998. Nuestros miedos. Perfiles Latinoamericanos 13: 179-198

Palmeira, M y B. Heredia. 1997. Política ambígua. En P. Birman, R. Novaes y S. Crespo (Ed) O mal á brasileira. Río de Janeiro, Ed UERJ.

Puex, N. 2006 Política y prácticas clientelares en las villas del conurbano bonaerense. En Míguez D y P. Semán Entre santos, cumbias y piquetes. Las culturas populares en la Argentina reciente. Buenos Aires, Biblos.

Puex, N. 2003 Las formas de la violencia en tiempos de crisis: una villa miseria en el conurbano bonaerense. En Isla, A. y D. Miguez (Ed) Heridas Urbanas. Violencia delictiva y transformaciones sociales en los noventa. Buenos Aires, Editorial de las Ciencias.

Quirós, J. 2006 Cruzando la Sarmiento. Una etnografía sobre piqueteros en la trama social del sur del Gran Buenos Aires. Buenos Aires, Antropofagia.

Weber, M. 1987 (1922) Economía y sociedad. FCE, México. 
